\title{
Candida Arthritis after Arthroscopic Arthroplasty in a Patient without Predisposing Factors
}

\author{
Chang-Hun Lee ${ }^{1}$, Jae-Min $\mathrm{Oh}^{2}$, Seong-Rheol $\mathrm{Oh}^{1}$, Minwook $\mathrm{Yoo}^{3}$ and Myeung-Su Lee ${ }^{*}, 1$ \\ ${ }^{1}$ Department of Medicine, Wonkwang University Hospital, Wonkwang University School of Medicine, 344-2 Shinyong- \\ Dong, Iksan, Jeonbuk 570-180, South Korea \\ ${ }^{2}$ Department of Anatomy, Wonkwang University School of Medicine, 344-2 Shinyong-Dong, Iksan, Jeonbuk 570-180, \\ South Korea \\ ${ }^{3}$ Department of Medicine, Public Health Center, Inchon City, South Korea
}

\begin{abstract}
Because candidiasis is usually associated with immunosuppression, candida arthritis in an immunocompetent patient is rare. The symptoms of candidiasis are similar to bacterial infections, tuberculosis, and autoimmune diseases. In our patient with no predisposing factors, candida arthritis was initially excluded because the probability of occurrence was low. The patient had no leukocytosis, the acid-fast bacteria (AFB) stain was negative, and the autoimmune antibody screen was negative. After Candida parapsilosis was cultured in the synovial fluid, the patient was treated with amphotericin B $(0.7 \mathrm{mg} / \mathrm{kg} / \mathrm{day})$ and oral fluconazole $(400 \mathrm{mg} / \mathrm{day})$. The treatment was successful and there were no side effects of the medications.
\end{abstract}

Keywords: Candida arthritis, arthroplasty.

\section{INTRODUCTION}

Candida arthritis is a very rare disease. And, most of the cases have been associated with immunosuppressive conditions, such as cancer, AIDS, organ transplantation, chronic renal failure, steroid use, and heroin abuse [1-6]. We present a patient with no predisposing factors who developed right knee arthritis caused by Candida parapsilosis 8 weeks after arthroscopic arthroplasty.

\section{CASE REPORT}

A 48-year-old woman was admitted to the Rheumatology clinic on 30 October 2008 with a 7-month history of pain and swelling in the right knee. The patient underwent arthroscopic arthroplasty 9 months before for relief of osteoarthritis pain. Because the pain and swelling in the right knee developed 7 months earlier, she underwent repeat arthroplasty 4 months before admission for removal of semilunar cartilage remnants. Despite the two arthroplasties, she continued to complain of pain and swelling.

Her medical history was negative for any rheumatoid diseases, cancer, renal diseases, and AIDS. She was a nonsmoker, and did not take any steroids, antibiotics, or illegal drugs. On physical examination, the patient had no rashes, lymph node enlargement, or hepatosplenomegaly. The patient's vital signs were as follows: blood pressure, 130/80 $\mathrm{mmHg}$; heart rate, $88 / \mathrm{min}$; respiratory rate, $20 / \mathrm{min}$; and body temperature, $36.8^{\circ} \mathrm{C}\left(98.2^{\circ} \mathrm{F}\right)$. The patient was alert and oriented, and there were no oral ulcers or erythema. The

*Address correspondence to this author at the Department of Medicine, Wonkwang University Hospital, Wonkwang University School of Medicine, 344-2 Shinyong-Dong, Iksan, Jeonbuk 570-180, South Korea; Tel: 82-63859-2550; Fax: 82-63-859-2245; E-mail: ckhlms@hanmail.net conjunctivae were not anemic and the sclerae were not icteric. A chest X-Ray showed a normal cardiac silhouette with no signs of pulmonary edema, and an EKG showed a normal sinus rhythm.

The laboratory results were as follows: WBC, $3100 / \mathrm{mm}^{3}$ $\left(4-10 \times 10^{3} / \mathrm{mm}^{3}\right)$; hemoglobin, $15 \mathrm{~g} / \mathrm{dL}(12-16 \mathrm{~g} / \mathrm{dL})$; PLT, $16.3 \times 10^{4} / \mathrm{mm}^{3}\left(15-45 \times 10^{4} / \mathrm{mm}^{3}\right)$; ESR, $41 \mathrm{~mm} / \mathrm{hr}(0-15$ $\mathrm{mm} / \mathrm{hr}) ; \mathrm{CRP}, 28.9 \mathrm{mg} / \mathrm{dL}(0-5 \mathrm{mg} / \mathrm{dL})$; total bilirubin, 0.6 $\mathrm{mg} / \mathrm{dL}$ (0.2-1.4mg/dL); AST/ALT, 23/11 IU/L (5-35/5-40 IU/L); ALP, $130 \mathrm{IU} / \mathrm{L}$ (32-122 IU/L); r-GTP, $16 \mathrm{IU} / \mathrm{L}$ (7-50 $\mathrm{IU} / \mathrm{L}) ; \mathrm{LDH}, 553 \mathrm{IU} / \mathrm{L}(100-450 \mathrm{IU} / \mathrm{L}) ; \mathrm{BUN} / \mathrm{Cr}, 11.2 / 0.8$ $\mathrm{mg} / \mathrm{dL}(8-20 / 0.5-1.3 \mathrm{mg} / \mathrm{dL})$; and uric acid, $2.2 \mathrm{mg} / \mathrm{dL}$ (2.5-8 $\mathrm{mg} / \mathrm{dL}$ ). Tests for anti-nuclear antibody (ANA), rheumatoid factor (RF), anti-dsDNA antibody, anti-Smith antibody, anti$\mathrm{Ro} / \mathrm{La}$ antibody, anti-RNP antibody, and HLA $\mathrm{B}_{27}$ were all negative. The $\mathrm{C}_{3}$ was $158 \mathrm{mg} / \mathrm{dL}(70-176 \mathrm{mg} / \mathrm{dL})$ and the $\mathrm{C}_{4}$ was $21 \mathrm{mg} / \mathrm{dL}(16-45 \mathrm{mg} / \mathrm{dL})$. The synovial fluid cytology findings were as follows: appearance, cloudy and reddish; WBC, $12,800 / \mathrm{mm}^{3}\left(0-200 / \mathrm{mm}^{3}\right)$ with $85 \%$ neutrophils and $10 \%$ lymphocytes; RBC, $8,320 / \mathrm{mm}^{3}\left(0-400 / \mathrm{mm}^{3}\right)$; protein, $3 \mathrm{~g} / \mathrm{dL}(1-3 \mathrm{~g} / \mathrm{dL})$; and glucose, $2 \mathrm{mg} / \mathrm{dL}(0-10 \mathrm{mg} / \mathrm{dL})$. No crystals were detected in the joint aspirate. The Gram stain and acid-fast bacteria (AFB) stain showed no bacteria or tuberculosis. Candida parapsilosis was cultured in the synovial fluid on hospital day 7 , which was confirmed on hospital day 8 .

On hospital day 2, the radiographs of both knees showed a mottled appearance of the distal femur and proximal tibia and asymmetric joint space narrowing (Fig. 1). A magnetic resonance imaging (MRI) of the right knee demonstrated a large joint effusion and enhanced synovium, indicating severe inflammation of the knee joint (Fig. 2). Amphotericin B $(0.7 \mathrm{mg} / \mathrm{kg} /$ day $)$ was given intravenously for 3 weeks. As the pain and swelling of the knee subsided, the amphotericin 
B was discontinued and oral fluconazole ( $400 \mathrm{mg} /$ day) was prescribed for 6 months. The last culture of synovial fluid was negative for $C$. parapsilosis and the patient had no complaints of pain or swelling.

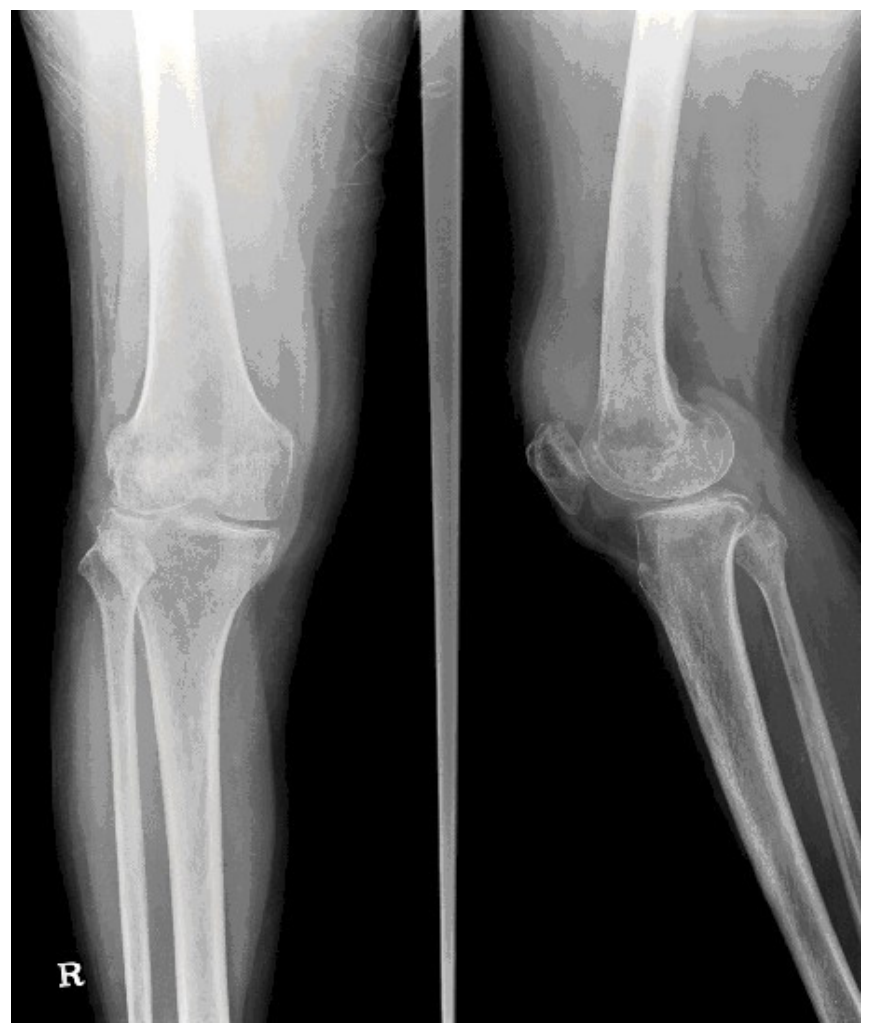

Fig. (1). Radiographs of both knee shows mottled appearance of distal femur and proximal tibia and also asymmetric joint space narrowing.

\section{DISCUSSION}

Candidiasis is uncommon in immunocompetent patients. Most affected patients who develop candidiasis in the knee are immunosuppressed with predisposing factors. For example, candidiasis is associated with autoimmune disease, HIV, chronic steroid use, cancer cachexia, and recreational drugs $[1,2,5-7]$. Our patient had a negative medical history with respect to immunosuppression, and did not have postoperative neutropenia. The patient reported herein complained of pain and swelling in the right knee, and $C$. parapsilosis was cultured from the synovial fluid of the knee 8 weeks after arthroplasty.

Septic arthritis or tuberculosis was initially suspected, and Candida was not considered as a cause because it is rarely reported in an immunocompetent patient; however, postoperative infectious arthritis caused by bacteria or tuberculosis is not rare in an immunocompetent patient [8]. Although symptoms of candida arthritis are similar to septic arthritis or tuberculosis, the incidence of candidiasis is much lower [9]. If a patient develops pain and swelling with rapid destruction of the knee on postoperative radiographs, septic arthritis or tuberculosis must be suspected prior to candida arthritis.
Having osteoarthritis in the right knee for a lengthy period of time, the patient had an arthroplasty without transplantation of prosthesis. There was no evidence of immunosuppression before or after surgery. The arthroscopic arthroplasty was performed under aseptic conditions. It has been reported that knee arthroplasty can cause candida arthritis, yet minimally invasive procedures such as arthroscopy have been not considered as a predisposing factor [10]. Postoperative infections occur in about $0.4 \%$ of patients when the arthritis is treated with arthroscopy [11].

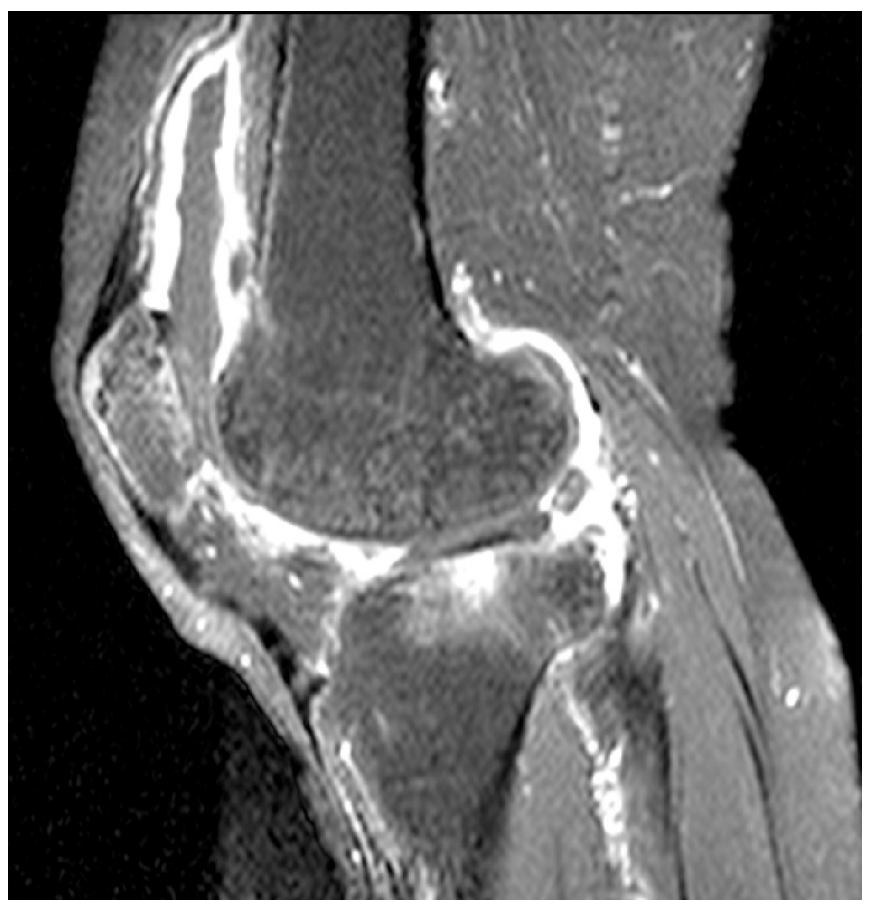

Fig. (2). Gadolinium enhanced $T_{1}$ weight MRI of right knee shows large amount of joint effusion and enhanced synovium indicating inflammatory arthritis.

Candida arthritis is treated with joint debridement and antifungal medications, such as amphotericin B (0.5 1 $\mathrm{mg} / \mathrm{kg} /$ day) and fluconazole (400mg/day) [12, 13]. If a knee infection results, removal of the prosthesis is also necessary [14]. The treatment of candida arthritis has not been established. Indeed, some cases of candida arthritis have been treated without the removal of prosthesis [13]. The response to fluconazole is variable. Because successful treatment with amphotericin $\mathrm{B}$ has been more reported, we initiated treatment with amphotericin $\mathrm{B}$, which was changed to fluconazole 3 weeks later. A long-term survey of candida demonstrated that fluconazole had fewer side effects and a superior antifungal effect than amphotericin B [15].

This represents the first report of candida arthritis developing in a patient without predisposing factors following arthroscopic arthroplasty. Candidiasis is generally asymptomatic, or only has pain and swelling in the knee [9], thus many cases are aggravated by a late diagnosis. If a patient complains of pain and swelling in the knee after arthroscopy, the possibility of a fungal infection should be 
considered. Although all minimally invasive procedures are not important risk factors for postoperative infection [10], candida arthritis should be in the differential diagnosis in a patient following arthroscopy.

\section{COMPETING INTERESTS}

The Wonkwang University Research Grant 2008 supported this study.

\section{CONSENT}

Full written consent was received for the manuscript to be published.

\section{REFERENCES}

[1] Sili U, Yilmaz M, Ferhanoglu B, Mert A. Candida krusei arthritis in a patient with hematologic malignancy: Successful treatment with voriconazole. Clin Infect Dis 2007; 45: 897-8.

[2] Legout L, Assal M, Rohner P, Lew D, Bernard L, Hoffmeyer P. Successful treatment of Candida parapsilosis (fluconazoleresistant) osteomyelitis with caspofungin in a HIV patient. Scand J Infect Dis 2006; 38: 728-30.

[3] Masoud M, Nasser NJ, Karban A, Edelstein S. Candida parapsilosis septic arthritis in a renal transplant patient. J Clin Rheumatol 2008; 14: 56.

[4] Kathresal A, Biundo J, Blais CM, Morse S, Reisin E. A rare case of Candida arthritis in a hemodialysis patient. Am J Med Sci 2008; 336: 437-40.
[5] Cuende E, Barbadillo C, E-Mazzucchelli R, Isasi C, Trujillo A, Andréu JL. Candida arthritis in adult patients who are not intravenous drug addicts: report of three cases and review of the literature. Semin Arthritis Rheum 1993; 22: 224-41.

[6] Jeragh A, Ahmad S, Naseem J, Khan ZU. Candida lusitaniae arthritis in an intravenous drug user. Mycoses 2007; 50: 430-32.

[7] Campen DH, Kaufman RL, Beardmore TD. Candida septic arthritis in rheumatoid arthritis. J Rheumatol 1990; 17: 86-88.

[8] Zhao X, Chen S, Deanda A Jr, Kiev J. A rare presentation of tuberculosis. Am Surg 2006; 72: 96-7.

[9] Kawanabe K, Hayashi H, Miyamoto M, Tamura J, Shimizu M, Nakamura T. Candida septic arthritis of the hip in a young patient without predisposing factors. J Bone Joint Surg Br 2003; 85: 734-5.

[10] Açikgöz ZC, Sayli U, Avci S, Doğruel H, Gamberzade S. An extremely uncommon infection: Candida glabrata arthritis after total knee arthroplasty. Scand J Infect Dis 2002; 34: 394-6.

[11] Paul J, Kirchhoff C, Imhoff AB, Hinterwimmer S. Infection after arthroscopy. Orthopedics 2008; 37: 1048, 1050-2, 1054-5.

[12] Zmierczak H, Goemaere S, Mielants H, Verbruggen G, Veys EM. Candida glabrata arthritis: case report and review of the literature of Candida arthritis. Clin Rheumatol 1999; 18: 406-9.

[13] Merrer J, Dupont B, Nieszkowska A, De Jonghe B, Outin H. Candida albicans prosthetic arthritis treated with fluconazole alone. J Infect 2001; 42: 208-9.

[14] Fukasawa N, Shirakura K. Candida arthritis after total knee arthroplasty-a case of successful treatment without prosthesis removal. Acta Orthop Scand 1997; 68: 306-7.

[15] Horn DL, Neofytos D, Anaissie EJ, et al. Epidemiology and outcomes of candidemia in 2019 patients: Data from the prospective antifungal therapy alliance registry. Clin Infect Dis 2009; 48: 1695-703.

(C) Lee et al.; Licensee Bentham Open.

This is an open access article licensed under the terms of the Creative Commons Attribution Non-Commercial License (http://creativecommons.org/licenses/by-nc/ 3.0/) which permits unrestricted, non-commercial use, distribution and reproduction in any medium, provided the work is properly cited. 